\title{
Clínica da voz: reflexões sobre a formação do alunado
}

\author{
Voice clinic: reflecting on undergraduate education
}

Flávia Fialho Cronemberger ${ }^{1}$

1 Doutora em Linguística pela PUCRS/PPGL UNEB/PPGEL (2014) e Mestre em Educação pela UNEB/PPGEduC (BA). Professora Adjunta do Curso de graduação em Fonoaudiologia da Universidade do Estado da Bahia (UNEB). Grupo de pesquisa: Grupo de estudos interdisciplinares em chua, linguagem e cultura

E-mail: flaviafialnoig.combr
RESUMO: Na história acadêmico-científica da Fonoaudiologia na área da clínica da voz destacam-se três diferentes concepções teóricas: um viés mais organicista, uma perspectiva mais psicanalítica e a clínica compreendida pela filosofia bakhtiniana. Analisando trabalhos publicados em periódicos nacionais, constata-se o predomínio de uma memória sócio-organicista no horizonte fonoaudiológico na área da clínica da voz. Questiona-se a partir de quais concepções teóricas, nos dias atuais, os professores que ministram as disciplinas em voz podem estar trabalhando. Nesse sentido, 0 objetivo principal deste artigo é apresentar aspectos constituintes do processo de formação de um aluno de graduação em Fonoaudiologia ocorridos em um estágio supervisionado na área da clínica da voz. A pesquisa é um recorte de um estudo maior em que se observaram integrantes de um estágio supervisionado na área de voz, durante um semestre letivo, produzindo enunciados em diferentes situações concretas de discurso. Foram filmadas supervisões, atendimentos clínicos e realizadas entrevistas com um grupo de alunas, uma professora e duas pacientes que compuseram um estágio supervisionado em uma instituição de ensino superior. Das gravações e observações realizadas, foram analisados alguns enunciados de uma professora, uma aluna e uma paciente. Observou-se que a estudante, ao compreender a clínica envolvida por uma abordagem com tendências mais organicistas e ao observar o sujeito de forma fragmentada, não em sua complexidade constitutiva, pouco valorizou a escuta das vozes da paciente no processo terapêutico. Pondera-se que a abordagem enunciativa-discursiva bakhtiniana, quando incorporada à formação do aluno, pode ajudá-lo a compreender mais as singularidades e complexidades que envolvem cada processo terapêutico, contribuindo para a realização de atendimentos clínicos e supervisões mais efetivas.

PaLAVRAS-CHAVE: Vozes bakhtinianas; Clínica da voz; Formação de estudantes.

ABSTRACT: In the academic and scientific history of speech therapy within the field of voice therapy, three different theoretical conceptions prevail a bias towards a more organicist approach, a more psychoanalytical perspective, and clinical therapy from within the perspective of Bakhtin's philosophy. Analyzing speech therapy articles published in Brazilian journals, the predominance of an organicist social-historical memory is apparent in the area of voice therapy. This fact raised questions regarding which theoretical conceptions are currently used by professors teaching voice courses. Therefore, the principal objective of this paper is to describe aspects involved in the training process of an undergraduate speech therapy student during supervised practice in the field of voice therapy. This study is part of a larger study in which students participating in supervised practice in the field of voice therapy were observed over one academic semester, resulting in the production of utterances in different concrete situations of discourse. Supervisions and clinical consultations were filmed and interviews were conducted with a group of female students, a female professor and two female patients during a period of supervised practice in an institute of higher education over one academic semester.

Of the recordings and observations made, some utterances made by the professor, one of the students and a patient were analyzed for this paper. 
Results showed that, by understanding that the clinic applied an approach with more organicist tendencies and by viewing the subject in a fragmented manner and not in her constitutive complexity, the student gave little importance to the patient's voices in the therapeutic process. The Bakhtinian concepts of discourse and utterance, when incorporated into the student's training, may increase his/her understanding of the singularities and complexities involved in each therapeutic process, thus contributing towards more effective clinical consultations and supervised practice.

KEYwORDS: Bakhtinian voices; Voice clinic; Student training.

\section{Introdução}

U levantamento realizado nas quatro principais revistas nacionais em Fonoaudiologia que abrangem estudos na área da voz - Revista da Sociedade Brasileira de Fonoaudiologia, Revista Cefac, Revista Distúrbios da Comunicação Humana e Pró-Fono, de 2007 a 2011, apontou que pesquisas envolvendo o perfil positivista/organicista ${ }^{1}$ são as mais recorrentes, em contraponto a outras concepções como a bakhtiniana e a psicanalítica. De 167 trabalhos publicados, 154 artigos abarcaram um perfil mais biologizante (CRONEMBERGER, 2014).

Frente a tal constatação, iniciou-se a pesquisa, questionando como se encontra, nos dias atuais, a formação dos alunos de graduação em Fonoaudiologia para atuar na clínica da voz. Indaga-se que terapeutas/ fonoaudiólogos estão sendo formados. Aquele que só vê a doença e/ou aquele que percebe o sujeito em sua complexidade constitutiva? A partir de quais concepções teóricas os alunos, futuros fonoaudiólogos, estão sendo formados? Caso os professores estejam trabalhando com uma concepção de

\footnotetext{
${ }^{1}$ Segundo Dunker (2000), a clínica com uma abordagem positivista/organicista busca compreender a doença que acomete o sujeito, entendendo-a em uma perspectiva mais biologizante. Como a base etiológica está fundamentada no viés orgânico, o diagnóstico advém de analises e exames de aspectos comportamentais e corporais do sujeito. A terapêutica privilegia a realização de técnicas e instrumentos que tragam resultados que comprovem a eficácia do tratamento. Os resultados são apresentados em termos percentuais e comparados à norma padrão. Nessa abordagem, pouco se atenta para o sujeito e toda a sua sócio historicidade constitutiva.
}

clínica com tendências mais organicistas, haveria consequências desse tipo de ação na formação dos estudantes?

Partindo dessa mirada, este artigo tem por objetivo apresentar aspectos constituintes do processo de formação de um aluno de graduação em Fonoaudiologia, durante um estágio supervisionado na área de voz, com o intuito de analisar as vozes que circularam em um atendimento e supervisão e os efeitos de sentidos presentes nessas vozes que ajudaram a formar o discente.

Buscando respaldo em Bakhtin (1920-1924/1993) para analisar as questões propostas, entende-se que o viés organicista, muitas vezes, não é capaz de tratar do sujeito nem do processo enunciativo com sua complexidade e multiplicidade de fatores que possibilitam ao indivíduo relacionar-se com o mundo. O filósofo compreende que o sujeito somente se constitui na relação com outro e é dessa constituição dialógica que precisa ser observado para ser melhor compreendido. Assim sendo, os fonoaudiólogos que seguem a teoria enunciativa bakhtiniana defendem que há pacientes que estabelecem uma relação conflituosa com a linguagem e consideram que esse conflito é de natureza social (MASINI, 2004). Nessa perspectiva, é necessário tratálos compreendendo suas relações interacionais constitutivas e os usos que fizeram e fazem da sua voz nas mais distintas relações com o outro.

A linguagem e a voz do sujeito materializam-se no momento em que ele interage com um determinado interlocutor, em certa situação, e manifestam 
(através das escolhas linguísticas e vocais) uma determinada valoração ao que está sendo dito. A clínica fonoaudiológica embasada por essa teoria entende que é de uma mirada social e subjetiva que o terapeuta inicia suas ações, a fim de compreender os sofrimentos vocais que acometem o sujeito.

Acreditando na importância da filosofia enunciativo-discursiva para uma atuação mais efetiva dos estudantes na clínica da voz, a análise do material selecionado segue princípios bakhtinianos concernentes à pesquisa no campo das ciências humanas. Dessa forma, compartilham-se experiências vivenciadas por um aluno, um professor e um paciente durante um atendimento e supervisão do caso.

O presente artigo é parte integrante de uma pesquisa de maior vulto em que foram observados e analisados enunciados - em diferentes situações concretas de discurso: atendimentos clínicos, supervisões e entrevistas - pelos sujeitos envolvidos em um estágio supervisionado durante um semestre letivo.

Nas análises é importante conseguir enxergar o fenômeno da ressonância dialógica e dos desdobramentos dessa onda de sentidos que colaboraram para a formação de um aluno na área da clínica da voz. Compreende-se que o fonoaudiólogo, ao perceber a força que o entrelaçamento de vozes tem na constituição dos indivíduos, poderá estar mais atento às filosofias e teorias que se segue na formação dos discentes.

\section{Abordagem dialógica}

O dialogismo, para Bakhtin, é um princípio intrínseco e constitutivo de todo discurso e se forma por "um compartilhar com o outro", instaurado a partir das interações sociais (DI FANTI, 2003, p. 98). Tendo o discurso uma natureza dialógica, conforme Bakhtin (1952-1953/1979/2003), a sua constituição responde à ressonância de enunciados já ditos, além de orientar-se para uma resposta antecipada, que é solicitada a surgir.

O locutor não é o primeiro sujeito a falar sobre o objeto de seu discurso, pois nele já se encontram tanto opiniões de interlocutores imediatos como visões de mundo, tendências, teorias, pontos de vista distantes, etc., que apresentam também seus posicionamentos valorativos. Todos esses aspectos constituem, para Bakhtin, parcelas do discurso do outro, que sempre repercutem no enunciado.

Assim, para o filósofo, todo discurso é atravessado por outros discursos (pontos de vista, posições sociais, etc.), ou seja, ele é tecido numa interação de inúmeras vozes. Nessa perspectiva, o sujeito, constituído e imbricado em seu meio social, é permeado e dialoga a todo o momento com os enunciados que o circundam (vozes que estejam no mesmo plano de sentido).

Todo discurso traz ecos de já ditos e responde a outros enunciados (presentes, passados e futuros). Na cadeia ininterrupta da comunicação discursiva, o enunciado, como elo, é orientado para outros enunciados, levando-se em conta as possíveis respostas dos seus interlocutores. Para o filósofo, o sujeito antecipa desde o início a compreensão ativa do seu interlocutor, pressupondo sempre sua resposta. Assim sendo, todo enunciado apresenta marcas da posição do sujeito enunciador dentro de um campo de sentidos frente a outros discursos.

Portanto, o indivíduo, enquanto ser social, constitui-se em uma arena de conflitos e confrontação de discursos (provenientes de interações sociais complexas). É nessa arena de conflitos que o sujeito vai escutando e assimilando os discursos e transformando-os, parte em palavras próprias e parte em palavras do outro. Di Fanti, estudiosa da teoria bakhtiniana, esclarece que, para o filósofo russo, o "outro aparece em diferentes graus de presença no enunciado, às vezes é visível, às vezes está escondido, mas sempre está lá, constitui um princípio alteritário", (2003, p. 98). 
Transpondo esse conhecimento para o objeto de estudo em questão, compreende-se que conhecimentos discutidos, trabalhados, singularizados e (re)significados no estágio advêm de relações dialógicas, muitas originárias de vozes constituintes do professor, alunos e pacientes que, em interação ao longo do estágio, renovam posicionamentos e o próprio atendimento clínico-terapêutico valorado por cada um. Nesse sentido, o estágio é um espaço de interação muito rico para o processo de aprendizagem acontecer, principalmente no que se refere ao aluno repensar seu papel como futuro terapeuta, desenvolvendo outras percepções em relação à teoria, às vozes que lhe constituem até o momento e aos outros com quem interage.

Dando continuidade ao pensamento bakhtiniano, o filósofo esclarece que "cada palavra se apresenta como uma arena em miniatura onde se entrecruzam valores sociais de orientação contraditória. A palavra revelase, no momento de sua expressão, como produto da interação viva das forças sociais" (1929/2008, p. 66). Há forças sociais que tendem a centralizar determinadas vozes discursivas, mas, ao mesmo tempo, há outras que tentam expandir as vozes, criando, dessa forma, zonas de grande e permanente tensionamento discursivo.

Nos periódicos nacionais em Fonoaudiologia (2007 a 2011), na área da voz, observa-se um predomínio de discursos de uma memória sócio histórica organicista (CRONEMBERGER, 2014). São forças centralizadoras atuando nos discursos fonoaudiológicos. O profissional, com essa visão, apresenta uma tendência em direcionar mais seu olhar para as emissões vocais do sujeito em comparação ao paciente singular, indivíduo multifacetado, com uma linguagem e voz constituídas em processo, a partir de inúmeras relações interativas/discursivas às quais é exposto.

Em contraponto, observam-se forças sociais que buscam descentralizar essa visão, com pesquisas e ações envolvendo outros enfoques teóricos, como o bakhtiniano. No entanto, há poucos trabalhos publicados nos periódicos nacionais em Fonoaudiologia envolvendo essas abordagens (CRONEMBERGER, 2014), fato que ajuda a centralizar o olhar de muitos fonoaudiólogos em uma perspectiva mais biologizante.

Conforme Bakhtin (1920-1924/1993, p. 73), "nós evocamos o fantasma da cultura objetiva, e agora não sabemos como exorcizá-lo". Nesse sentido, pondera-se que um grande número de fonoaudiólogos, não percebendo, reconhecendo e/ou se aprofundando em estudos acerca de outras vozes teóricas, perpetuam um olhar com tendências mais positivistas às práticas fonoaudiológicas, aspecto que contribui para restringir o campo de ação do profissional e, consequentemente, a visão do paciente que procura e solicita ajuda.

Assim sendo, analisar aspectos constituintes do processo de formação do estudante de Fonoaudiologia com o objetivo de refletir e/ou aprofundar conhecimentos dos professores em outras concepções teóricas, torna-se curioso e instigante, sendo a perspectiva bakhtiniana uma possibilidade a ser levada para os docentes visando à compreensão do sujeito em sua plenitude e transformação vocal.

\section{Metodologia}

Esse estudo é uma pesquisa de caráter qualitativo que segue princípios bakhtinianos concernentes à pesquisa no campo das ciências humanas.

No artigo são analisadas relações dialógicas presentes no primeiro atendimento de uma estudante a uma paciente, bem como a supervisão acadêmica do caso. Visando compreender melhor as vozes constituintes dos sujeitos em análise, foram examinados enunciados de entrevistas realizadas com estudantes e a professora.

A pesquisa é um recorte de um estudo maior em que se observaram integrantes de um estágio supervisionado na área de voz durante um 
semestre letivo. O estágio aconteceu no último semestre de um curso de graduação. Todos os alunos já haviam cursado disciplinas teóricas em voz e outro estágio curricular nessa área.

Os nomes dos sujeitos que aparecem a seguir são fictícios (professora: Ana, alunas: Carla, Judite, Sílvia e Lila e paciente: Valéria). Os enunciados dos sujeitos encontram-se transcritos em itálico, respeitadas as normas do projeto NURC (2000). A pesquisa passou pela análise do Comitê de Ética em pesquisa da PUCRS (Pontifícia Universidade Católica do Rio Grande do Sul), sendo aprovado com o CEP 11/05567.

\section{Análises}

As análises estão divididas em duas sessões: "O atendimento" e "A supervisão".

\subsection{0 atendimento}

Cabe apontar algumas vozes constituintes da discente nominada Carla e da docente Valéria que ajudam a compreender melhor a construção dos enunciados analisados no atendimento e na supervisão.

A aluna Carla e suas colegas encontram-se no último semestre de um curso de graduação em Fonoaudiologia e realizam o último estágio supervisionado na área da clínica da voz. A discente participou de outro estágio e outras disciplinas teóricas (em voz) que a formaram. Assim sendo, possuía uma bagagem prévia acerca da teoria e da prática clínica na área de voz. Na entrevista com as alunas, ao serem questionadas sobre o que haviam aprendido com disciplinas anteriormente cursadas na área da voz, enunciaram: Judite: “(...) principalmente ... tratar a patologia (...)”, Sílvia: “(...) buscar técnicas (...)”, Lila: “(...) os exercícios ... o que é indicado para tal patologia (...)". Isso indica uma formação em que parece predominar uma visão organicista da clínica, que valora a detecção da patologia e a realização de exercícios vocais, visando à melhora do paciente.

A professora Ana, em entrevista, refere uma formação clínica mais positivista, se comparada a outras abordagens, como a psicanalítica e a bakhtiniana. Ao ser questionada acerca de docentes marcantes em sua vida como estudante de graduação e fonoaudióloga, na área da clínica da voz, afirma: “(...) eu acho que Júlia não tem como não (...) posteriormente Kátia (...) acho que são dois ícones (...) são as sumidades (...) você tem Júlia que é muito organicista e você tem Kátia que pensa na questão da funcionalidade (...) acho que se complementam (...) você pega Júlia que tem a questão orgânica de fato e você pega Kátia (...) a questão do ajuste muscular (...)".

Por outro lado, percebe-se, em outros discursos da professora, a presença de vozes que flexibilizam seus enunciados: “(...) o final da história é que a disfonia é o reflexo de como o sujeito é (...)", apontando para uma gama de fatores constitutivos da voz do indivíduo: “(...) questões psíquicas (...) questões sociais que podem levar à disfonia (...)”. Por vezes, os dizeres de Ana tangenciam para as alunas a importância das relações dialógicas constituindo o sujeito e sua voz: “(...) tem o uso da voz profissional ... alguma coisa mais mudou na vida dela para que nestes dois últimos anos tenha ficado disfônica ... ou mudou turma ... ou pegou uma turma que ela agora não tá aguentando (...) ou além disso tá separando do marido ... então a gente sabe que a disfonia a gente tem muitas coisas juntas (...)". Dizeres que entoam distintas relações que podem piorar um quadro disfônico em um professor (na sala de aula: relação docente/discente, e na vida familiar: relação marido/esposa).

No entanto, embora se observem nos enunciados da professora valorações que apontam para outras possibilidades de se compreender um quadro de disfonia, as alunas atêm-se, como se verá adiante, àquelas que lhes provocam mais ondas de ressonância dialógicas, provavelmente, vozes que 
ecoam da formação das discentes ao longo da graduação, com tendências mais organicistas.

Ingressando mais propriamente nas análises, no primeiro atendimentoterapêutico da discente Carla no estágio em questão, Valéria, a paciente, entrega o resultado do seu exame laringológico (exame da laringe e das pregas vocais, realizado pelo otorrinolaringologista) à estudante. $\mathrm{Na}$ entrevista inicial, a paciente enuncia:

Valéria: “(...) eu falo muito rouca (...) quando eu tô no telefone eu sou confundida com homem (...) eu me sinto nervosa também quando eu tô falando (...) eu fiz uns exames há um tempo ... uns cinco anos atrás (...) eu tenho as cordas vocais abertas (...)".

Carla: No início antes de fazer o exame ... a senhora sentia alguma modificação na sua voz? ... sentia que tinha algo diferente? ... algo que te incomodava na voz antes de fazer o exame? ...

Valéria: Sentia ...

A paciente apresenta queixas que se relacionam ao uso da voz: “(...) quando eu tô no telefone eu sou confundida com homem (...) eu me sinto nervosa também quando eu tô falando (...)". Queixas que surgem "quando é necessário estabelecer uma comunicação com o outro", ou seja, quando a voz se mostra "implicada com a linguagem oral e é nesta que ganha sentido" (MÄRTZ, 1999, p. 206).

Observa-se que Carla não se aprofunda em questionamentos visando compreender melhor as relações interacionais que envolvem as reclamações da paciente. Sua atenção volta-se para outros dizeres de Valéria: “(...) eu fiz uns exames há um tempo ... uns cinco anos atrás (...) eu tenho as cordas vocais abertas (...)". A paciente comenta sobre um exame laringológico que realizou há uns cinco anos, em que foi constatado que tinha as pregas vocais abertas à fonação, ou seja, presença de uma fenda (hiato) entre as pregas no momento da produção da fala.

Frente a tal enunciado, a aluna Carla replica: "No início antes de fazer o exame ... a senhora sentia alguma modificação na sua voz? ... sentia que tinha algo diferente? ... algo que te incomodava na voz antes de fazer o exame?". A estudante verifica a presença de queixas na emissão vocal da paciente antes do período em que realizou o primeiro exame laringológico (há cinco anos), sugerindo suspeitar de algo. Valéria responde: "Sentia". Nos enunciados que se seguem, Carla parece querer averiguar suas suposições diagnósticas e busca pelo período em que a paciente começou a apresentar a alteração vocal:

Carla: entre a senhora começar a perceber essas dificuldades relacionadas à voz e procurar um médico ... demorou quanto tempo? ... sempre foi assim? ... a vida toda?...

Valéria: sempre fui ... sempre fui assim ...

Carla: sempre foi assim ... desde criança tinha essa voz? ...

Valéria: não ... desde criança não ... não me lembro do tempo que eu comecei ... que eu comecei a ver que eu tinha rouquidão ...

Uma pergunta é elaborada pela estudante como se desconfiasse de um possível diagnóstico para o quadro de rouquidão enunciado por Valéria: "entre a senhora começar a perceber essas dificuldades relacionadas à voz e procurar um médico ... demorou quanto tempo? ... sempre foi assim? ... a vida toda? (...)", parecendo inferir a chance de a paciente ser portadora de alguma alteração estrutural mínima da laringe ${ }^{2}$. Muitas dessas alterações

2 Segundo Pinho (1998, p. 65), "as alterações estruturais mínimas da laringe (AEM) são pequenas alterações na sua configuração, que incluem desde simples variações anatômicas até malformaç̃os menores, com imp a embriofênese". Muitos sujet. As portadores de tal quadro podem apresentar voz mais grave, dificuldade para regular a intensidade, tensão, aspereza, soprosidade e instabilidade vocal à fonação. 
são congênitas, por isso é muito frequente o sujeito apresentar um quadro disfônico desde a infância. Afora isso, as vozes dos laudos laringológicos, de cinco anos atrás e o atual, parecem ajudá-la a supor tal diagnose (primeiro exame laringológico: presença de fenda e laudo atual: presença de fenda fusiforme).

Nos quadros disfônicos com alterações estruturais mínimas da laringe, é comum a presença de fenda nas pregas vocais à fonação. Valéria responde: "sempre fui ... sempre fui assim ... ". Frente à réplica assertiva da paciente, a terapeuta questiona novamente Valéria e solicita uma resposta ainda mais precisa, provavelmente, buscando por uma maior certeza quanto ao diagnóstico que infere: "sempre foi assim ... desde criança tinha essa voz? (...)". A paciente refrata outra possibilidade de resposta: "não ... desde criança não (...)".

Observando tal posicionamento, pondera-se que vozes organicistas, ao longo da graduação, refletem nos enunciados de Carla à paciente Valéria. Os discursos da discente, no atendimento, são respostas a algo já dito antes, atravessados por entonações que valoram positivamente a procura por doenças gerando/mantendo um quadro disfônico.

Durante o atendimento, a aluna percebe a presença de um sinal persistente na paciente: tosse. Carla questiona Valéria sobre tal fato:

Carla: essa tosse que você está aí agora ... também ... é normal ou é por alguma coisa? ... alergia? ... tá gripada? ...

Valéria: não não tô gripada não ... às vezes acontece assim deu ficar tossindo e não é nem gripe ...

(...)

Carla: já falaram alguma vez ... já chegaram a falar sobre refluxo ... se a senhora teria refluxo? ...

Valéria: todos os exames que eu fiz não deu não (...)
Com suas perguntas, a aluna parece inferir uma relação entre a tosse e a existência de outra alteração agravando a voz de Valéria: "essa tosse que você está aí agora ... também ... é normal ou é por alguma coisa? ... alergia? ... tá gripada? ... ". Valéria responde: "não não tô gripada não ... às vezes acontece assim deu ficar tossindo e não é nem gripe ... ". Frente a tal réplica, em que é descartada a tosse ser proveniente de gripe, Ana percebe a possibilidade da doença do refluxo estar presente em Valéria e enuncia: "já falaram alguma vez ... já chegaram a falar sobre refluxo ... se a senhora teria refluxo? ... ". Nesse momento, sobressai, no discurso, a procura pela doença do refluxo gastroesofágico ${ }^{3}$; mais uma alteração que parece justificar o quadro vocal apresentado pela paciente (desconsiderando outras possíveis causas geradoras da tosse). Valéria enuncia que, dentre os exames de saúde que realizou, nenhum detectou tal patologia: "todos os exames que eu fiz não deu não (...)". Mesmo após tal posição da paciente, observa-se, ao longo do atendimento, que a aluna continua a buscar outros enunciados que tragam pistas dela ser portadora dessa enfermidade, como se constata a seguir:

Carla: (...) cê já sentiu alguma vez sensação de azia ... de queimação? ... Valéria: já ... já tive ... sensação de queimação (...) que eu até tomei remédio (...)

Carla: o refluxo ...

Valéria: não ... deu gastrite (...)

A aluna enuncia: “(...) se já sentiu alguma vez sensação de azia ... de queimação? ... ". A paciente responde: "já ... já tive ... sensação de queimação

3 Conforme Bittante de Oliveira (2004, p. 13), o refluxo gastroesofágico ou doença do refluxo gastroesofágico (DRGE) "consiste em retorno do suco gástrico pelo esôfago e, quando atinge a lairnge e a faringe, é considerado refluxo laringofaríngeo, também uma manifestação da doença do refluxo" podendo ocasionar/agravar um quadro de disfonia, além de provocar tosse, ardor, queimação, malestar etc. 
(...) que eu até tomei remédio (...)". Com tal réplica, Valéria apresenta sintomas (azia e queimação) que aparecem em várias enfermidades (gastrite, úlcera, refluxo, questões emocionais, etc.). Porém, como o sentido que a aluna busca nas respostas da paciente parece recair sobre uma possibilidade diagnóstica, Carla afirma: "o refluxo". Valéria discorda e pontua: "não ... deu gastrite".

Nos enunciados da aluna ecoam discursos já ditos que apontam para a importância da doença do refluxo agravando a voz do paciente. Palavras como as da professora Ana que, na primeira aula de supervisão do estágio (em que foram relembradas questões teóricas acerca do atendimento clínico), valorou para as alunas a importância de se pesquisar, na entrevista inicial, a presença do refluxo impedindo a melhora de um quadro disfônico em um paciente: “(...) então o refluxo e a alergia realmente é o que ganha ... são as doenças crônicas que mais emperram uma melhora do quadro vocal (...)". Aspecto muito importante de se considerar, mas que, associado a uma formação, ao longo do curso de graduação, com tendências mais organicistas, contribuiu para que a estudante se concentrasse, durante a entrevista inicial, em questões mais biologizantes com a paciente.

Além disso, considera-se que outras vozes influenciaram a construção do discurso da aluna, como aquelas que advêm da própria experiência de Carla em ser portadora de tal patologia. A discente enuncia as limitações pessoais que a doença do refluxo trouxe para sua vida na primeira supervisão do estágio: “(...) eu tenho que parar de tomar café (...) tenho tosse e pigarro como se fosse uma cola na garganta por causa do refluxo (...)". Assim, observa-se que tanto dizeres acerca da teoria positivista, ao longo da formação acadêmica da aluna, quanto vozes da experiência de vida da discente (como portadora da doença do refluxo) parecem ajudar a construir os enunciados da estudante, que supõem (pela ocorrência de sintomas como tosse e azia) a presença da doença do refluxo em Valéria. Como Oliveira e Friedman (2006) pontuam, ao se referir à clínica fonoaudiológica que trabalha em uma concepção organicista, sintomas corporais são entendidos como indicativos de doenças

Cabe lembrar que Bakhtin (1929/2010) refere que qualquer discurso não se relaciona apenas com os já ditos anteriores, mas também com os posteriores. Assim sendo, verifica-se que, no atendimento, a aluna constrói seu enunciado para Valéria tendo em vista tanto a paciente (interlocutora mais próxima), quanto o interlocutor professor (nesse caso, o terceiro, o supradestinatário: espectador). 0 filósofo pontua,

O referido terceiro não é algo místico ou metafísico [ ... ]; é o elemento constitutivo do enunciado total, que numa análise mais profunda pode ser nele descoberto. Isso decorre da natureza da palavra, que sempre quer ser ouvida, sempre procura uma compreensão responsiva (1959-1961/2003, p. 333).

Nesse sentido, a figura do terceiro, (no caso, a professora que não se encontra na sala de atendimento), além do destinatário mais próximo (a paciente), são muito importantes para a constituição do discurso da aluna. Pode-se pensar que Carla, ao considerar a figura da docente (aquela que irá almejar um diagnóstico), constrói enunciados valorando a procura por doenças (alguma alteração estrutural mínima da laringe e a doença do refluxo) que justifiquem o quadro vocal que acomete a paciente.

Nesse dia de atendimento, apesar de os discursos da aluna procurarem por réplicas que confirmem certas patologias, observam-se, nos dizeres da paciente, entonações que valoram o sofrimento que sua voz lhe traz no dia a dia. Sensações desencadeadas, provavelmente, no momento em que usa a voz para interagir com o outro: "(...) é assim quando eu tô mais nervosa ... fico mais rouca (...)"; "(...) fico ansiosa e frustrada por causa da voz (...)"; “(...) fico deprimida por causa da voz (...)". Entretanto, percebe-se que esses enunciados parecem possuir um valor secundário para a discente, já que não busca compreendê-los de forma mais aprofundada no atendimento. 
A aluna anota as posições da paciente em uma folha, sem realizar outros questionamentos sobre o assunto.

Pensando acerca da posição da aluna, os escritos parecem funcionar como informações que ajudam a descrever o quadro patológico da paciente para a professora; possíveis restrições que as alterações vocais trazem para a vida do sujeito. Segundo Dunker (2000), em uma concepção organicista/ positivista, o terapeuta ouve o sujeito, mas não o escuta, uma vez que as informações captadas e valoradas são aquelas que ajudam a delinear uma determinada patologia. 0 projeto enunciativo de Carla, nesse dia, parece não reconhecer as várias demandas da paciente, mas sim, isolar aqueles elementos da sua fala que lhe têm valoração maior, visando à compreensão de prováveis patologias que acometem Valéria.

Na procura por um diagnóstico que explique a voz alterada da paciente, a aluna parece direcionar as perguntas que faz para delimitar um quadro patológico para o caso. Pondera-se que a discente, aparentemente sem compreender a complexidade de aspectos que compõem o discurso de Valéria, não se deixa afetar pelo desconhecido e singular que os enunciados da paciente trazem e que podem possibilitar o encontro com outras vozes que elucidem melhor o quadro vocal apresentado.

\subsection{A supervisão}

Carla discorre sobre informações que coletou com a realização da entrevista inicial:

Carla: Valéria tem 40 anos ... ela veio com a queixa da voz ser muito rouca (...) ela se conhece rouca ... desde que se conhece por gente (...) fez tratamento de gastrite há um ano ... tomou medicação e não observou relação com melhora ou piora da voz ... só sentia azia e não chegava a ter o refluxo e pronto (...).
Carla descreve a história da paciente para os participantes da supervisão com as seguintes considerações: a paciente ser rouca e se conhecer rouca desde pequena e apresentar problemas gastroesofágicos. Tais valorações parecem levar a professora e as alunas a duas possíveis conclusões do caso.

A primeira, “(...) ela veio com a queixa da voz ser muito rouca (...) ela se conhece rouca ... desde que se conhece por gente (...)", sugere um possível quadro de alguma alteração estrutural mínima na laringe. A segunda, “(...) fez tratamento de gastrite há um ano ... tomou medicação e não observou relação com melhora ou piora da voz ... só sentia azia (...)", indica a presença de uma doença gastroesofágica. Nesse sentido, verifica-se um direcionamento no enunciado da aluna a prováveis alterações que acometem a paciente e prejudicam a sua voz. Com a palavra “(...) e pronto (...)", a estudante parece acreditar que apresenta Valéria aos participantes da supervisão, mas, na verdade, apenas aponta as alterações fisiológicas que interpreta durante o atendimento.

Outro aspecto interessante de ser considerado relaciona-se à estudante trazer, em seus dizeres, sentidos que não foram acentuados pela paciente. Na supervisão, a aluna enuncia: “(...) enfim ela se conhece rouca ... desde que se conhece por gente (...)". No atendimento, quando a estudante questionou a paciente sobre a presença da rouquidão desde a infância, Valéria respondeu: "não ... desde criança não (...)". Assim, observam-se, nos enunciados da aluna (em supervisão), palavras da paciente com certa distorção de sentido.

Outro fato semelhante acontece nesse mesmo dia de supervisão. A aluna Carla enuncia: “(...) tomou remédio nessa época pra gastrite ... pro refluxo ... sempre pigarro constante e uma tosse constante também (...)". No atendimento, Valéria referiu não ser portadora da doença do refluxo: "todos os exames que eu fiz não deu não (...)". Embora, inicialmente, ao apresentar a paciente na supervisão, Carla refrate a possibilidade dela não ter refluxo: "só sentia azia e não chegava a ter o refluxo (...)", segue, em outros enunciados, 
apontando a paciente ser portadora de tal enfermidade. Cabe pontuar que, durante o atendimento, a paciente enunciou que o pigarro e a tosse não eram constantes no seu dia a dia: “(...) às vezes eu fico com pigarro e tosse (...)". Tal sentido é modificado na supervisão, “(...) sempre pigarro constante e uma tosse constante também (...)", e reflete a procura da aluna em apresentar doenças que justifiquem a rouquidão da paciente para a professora.

Enquanto, no atendimento, a professora se encontra como interlocutora supradestinatária, na supervisão posiciona-se como interlocutora mais próxima para quem a aluna constrói seus enunciados. Parecendo considerar a docente aquela que quer conhecer um diagnóstico que explique o quadro vocal alterado da paciente, Carla traz em seus dizeres palavras de Valéria com certa distorção de sentido, a fim de justificar a voz alterada da paciente. Tanto no atendimento quanto na supervisão, a posição da professora como interlocutora parece ser muito valorada na construção dos enunciados da aluna.

Já a posição da paciente (também interlocutora da aluna) parece ser, para a estudante, aquela que fornece informações que contribuem para delinear um diagnóstico a ser apresentado para a professora. Compreende-se que, envolvida por uma formação mais organicista, Carla construa tais visões da paciente e da professora que repercutem na construção dos seus enunciados e que acentuam positivamente discursos biologizantes da paciente (algumas vezes até distorcendo palavras de Valéria em prol dessa concepção) para o entendimento do caso pela docente.

A professora Ana lê o laudo laringológico da paciente e questiona Carla:

Ana: essa assimetria de fase ... ou é por edema ou é porque tem alguma coisa aí ... Carla: é rouca ... áspera ...

Ana: então assim ... desde que ela é criança que ela acha que é rouca? ...

Carla: hum ((balançando a cabeça afirmativamente)r) (...)

Ana: minha gente ... quais são as alterações estruturais mínimas possíveis? ...
A professora aponta para prováveis alterações que podem estar acometendo as pregas vocais de Valéria: "essa assimetria de fase ... ou é por edema ou é porque tem alguma coisa aí (...)”. Refere que a presença de um edema (inchaço nas pregas vocais) ou outras alterações podem estar afetando as pregas vocais da paciente. Verifica-se que a aluna, ao construir sua réplica a esse enunciado, ajuda a delimitar um diagnóstico para a docente.

Nesse sentido, as palavras da estudante, "é rouca ... áspera", trazem pistas que assinalam uma provável alteração acometendo a laringe da paciente (alguma alteração estrutural mínima da laringe). Pondera-se que a professora, embasada em suas suposições em relação às alterações que acometem as pregas vocais de Valéria (ao ler o laudo laringológico da paciente) e nas pistas enunciativas trazidas pela aluna, constrói um enunciado, questionando as estudantes sobre o conceito das alterações estruturais mínimas da laringe: "minha gente ... quais são as alterações estruturais mínimas possíveis? ..."

Verifica-se que a docente, em interação com a aluna, traz uma visão que busca ampliar os conhecimentos das discentes ao questioná-las sobre o conceito de tais alterações. Assim sendo, observa-se que tanto os enunciados da docente para a discente quanto os enunciados da aluna para a professora acabam por reforçar, em ambas, um conhecimento positivista acerca do caso. Essa espécie de concordância vem ao encontro do que explica Bakhtin (1929/2010, p. 117) sobre a palavra: "constitui justamente o produto da interação do locutor e do ouvinte".

Nesse dia de supervisão, observa-se em diálogos da professora com outras alunas, como por exemplo, a discente Judite, uma abertura maior da docente para tratar de assuntos não direcionados à patologia. Judite pontua: "ele disse que gosta de ir para balada”. A professora responde: “(...) pergunta se quando ele fala com os amigos e tal ele fica rouco? (...)". Ana solicita que a aluna verifique se o aparecimento e/ou agravamento da rouquidão no paciente de Judite relaciona-se a momentos em que faz uso da sua voz para se comunicar 
com outros. Nesse aspecto pondera-se acerca do tanto que os enunciados trazidos pelos alunos, interferem na construção dos dizeres da professora, tornando as palavras da docente, mais ou menos, centralizadas nas questões patológicas, valorando diferentes possibilidades de compreensão da clínica para as estudantes.

Em contrapartida, as distorções enunciadas pela aluna Carla de a paciente Valéria não ser portadora de refluxo e não recordar rouquidão desde infante não são motivo de reflexão em supervisão. A professora não presenciou, no dia em foco, toda a situação concreta de atendimento e, nesse sentido, não escutou todos os posicionamentos da paciente ao longo da sessão.

Ao mesmo tempo, constata-se que, em uma situação de estágio, com um grupo de alunos atendendo pacientes concomitantemente, torne-se difícil para a professora observar cada atendimento do início ao fim, podendo, por isso, não captar possíveis distorções entre o atendimento e o seu relato em supervisão. Caso a filosofia bakhtiniana fosse abarcada, a aluna estaria mais atenta à escuta das vozes da paciente e não focada em questões orgânicas, realizando uma leitura mais abrangente do caso.

Vislumbra-se, nos enunciados analisados, a intensa rede de fios dialógicos que constroem os discursos de aluna e professora (vozes da professora se projetando no discurso da aluna e vozes da aluna se projetando nos discursos da professora), refletindo nos enunciados posições de cunho mais organicista. Nessa perspectiva, observa-se uma redução dos dizeres da paciente Valéria relacionadas à sócio historicidade constitutiva da sua voz.

\section{Discussão}

Tanto no atendimento quanto na supervisão, a posição da professora como interlocutora parece ser muito valorada na construção dos enunciados da aluna. Já a posição da paciente (também interlocutora da aluna) parece ser, para a estudante, aquela que fornece informações que contribuem para delinear um diagnóstico a ser apresentado para a professora. Compreende-se que, envolvida por uma formação mais positivista, a estudante construa tais visões da paciente e da docente, que repercutem na elaboração dos seus enunciados e que acentuam positivamente discursos biologizantes da paciente para o entendimento do caso pela professora.

Com tal concepção de clínica, provavelmente advinda de vozes de uma formação acadêmica e pessoal da estudante com valores mais organicistas, a discente Carla constrói enunciados distorcendo alguns posicionamentos da paciente para a professora, em prol da determinação de um diagnóstico patológico.

A docente, por sua vez, ao escutar as palavras da estudante, elabora réplicas embasadas nas posições da discente, que, conforme dito acima, por vezes, apresenta algumas distorções em relação ao relato da paciente. Aspecto que tanto fragmenta a leitura do caso pela professora, como ajuda a direcionar, com as respostas da docente (envolvida pelas vozes da aluna), para um entendimento reducionista do quadro (viés mais patológico).

Pode-se perceber, por conseguinte, uma certa dificuldade da professora em reconhecer, em supervisão, as distorções enunciadas pela aluna acerca dos atendimentos. Isto se deve à própria organização dos estágios na área de saúde, o que impossibilita a participação concreta do docente em todos os atendimentos acadêmicos, já que acontecem em um mesmo horário para muitos alunos.

Considerando esse cenário, é muito difícil para a professora reconhecer possíveis distorções na fala da estudante. Uma mudança nesse quadro passa pelo entendimento de uma concepção mais abrangente da Fonoaudiologia na área da voz que possibilitaria à discente escutar outras vozes constituintes da paciente.

Verifica-se, portanto, que a aluna, ao não se abrir para compreender a complexidade de aspectos que compõem o discurso da paciente (fora os que 
levam a um entendimento biologizante do caso), não se deixa afetar pelo desconhecido e singular que os enunciados de Valéria trazem. Os discursos analisados, possivelmente, levariam a outras reflexões e, quem sabe, outros caminhos terapêuticos ao longo dos atendimentos e supervisões.

\section{Considerações Finais}

Pensando a partir de um ponto de vista bakhtiniano, percebe-se que o entendimento pelo aluno da complexidade constitutiva do paciente precisa estar no centro da sua formação. Ao se valorar mais uma faceta do indivíduo (orgânica), pode-se acabar colocando para um segundo plano os sujeitos e suas historicidades, no processo terapêutico.

A aproximação do estudante aos estudos bakhtinianos o ajudaria a compreender a importância das interações que constituem o paciente e sua voz, uma vez que tal concepção reconhece que a formação do homem é um fato sócio-ideológico. Apesar de não deixar de considerar os princípios biológicos, a abordagem bakhtiniana entende que os processos que definem o indivíduo (e sua linguagem/voz) não são internos, mas se encontram fora do organismo.

Nessa perspectiva, torna-se importante que o professor trabalhe mais com os alunos a escuta das vozes do paciente. Abrir possibilidade para o estudante observar novas entoações o ajudaria a compreender melhor o que acontece com o sujeito, contribuindo para resolver a relação conflituosa que o indivíduo apresenta com a sua voz.

\section{Referências}

BAKHTIN, M. Para uma filosofia do ato. Trad. Para uso didático feita por C. Tezza e C.A. Faraco, 1993 [1920-1924].
BAKHTIN, M. O problema do texto na linguística, na filologia e em outras ciências humanas (1959-1961). In: Estética da criação verbal. Trad. Paulo Bezerra. São Paulo: Martins Fontes, 2003, p. 307-336 [1959-1961].

[VOLOSHINOV]. Marxismo e filosofia da linguagem. Trad. Michel Lahud e Yara Frateschi Vieira. 14. ed. São Paulo: Hucitec, 2010 [1929].

. O discurso no romance. In: Questões de literatura e de estética: a teoria do romance (1975). Trad. Aurora Fornoni Bernardini, José Pereira Júnior, Augusto Goés Júnior, Helena Spryndis Nazário, Homero Freitas de Andrade. 6. ed. São Pulo: Hucitec, 2010, p. 71-210 [1934-35].

BITTANTE DE OLIVEIRA, I. Avaliação Fonoaudiológica da voz: reflexões sobre condutas com enfoques à voz profissional. In: FERREIRA, L. P.; BEFI-LOPES, D. M.; LIMONGI, S. C. O. (Orgs.). Tratado de Fonoaudiologia. São Paulo: Roca, 2004, p. 11-24

CRONEMBERGER, F. F. Aspectos da formação do estudante de graduação em Fonoaudiologia na clínica da voz: por uma abordagem enunciativa bakhtiniana. Tese de Doutorado em Letras. Pontifícia Universidade Católica do Rio Grande do Sul. Porto Alegre, 2014.

DI FANTI, M. G. C. A linguagem em Bakhtin: pontos e pespontos. Revistas de Estudos Linguísticos VEREDAS, Juiz de Fora, v. 7, n. 1, p. 95-111, 2003.

DUNKER, C. I. L. Clínica, linguagem e subjetividade. Revista Distúrbios da Comunicação, São Paulo, v. 12, n. 1, p. 39-60. 2000.

MASINI, M. L H. O diálogo e seus sentidos na clínica fonoaudiológica. Tese de Doutorado em Linguistica aplicada e estudos da linguagem. Pontifícia Universidade Católica de São Paulo, São Paulo, 2004.

MÄRTZ, M. L. W. Algumas reflexões sobre a terapia da voz. Revista Distúrbios da Comunicação, São Paulo, v. 10, n. 2, p. 205-211, 1999.

PINHO, S. M. R. Tratando os distúrbios da voz. São Paulo: Guanabara Koogan, 1998.

Recebido em 30/11/2015 Aceito em 28/04/2016. 